\title{
Turning the Inside Out: Presuppositions of Alberta Educational Leaders Promoting Progressive Reform, c. 1920-1950
}

\author{
Lynn Lemisko \\ University of Saskatchewan
}

\begin{abstract}
Alberta's educational leaders appeared to be taking united collective action in promoting progressive programs and pedagogy, c. 1920 to 1950 . However, there were deep differences in their presuppositions about human nature and the relationship among human beings that shaped their ways of thinking about what students needed to know and how students learned. Utilizing a methodology advocated by R. G. Collingwood, this study reveals these differing presuppositions and argues that three predominant and conflicting ways of thinking among Alberta's educationists - that is, conservative, liberal, and collectivist - had an invisible but significant impact on their educational reform efforts.
\end{abstract}

\section{RÉSUMÉ}

Entre 1920 et 1950, des spécialistes en éducation albertains ont semblé prendre une action collective en faveur de programmes et d'une pédagogie progressistes. Cependant, de profondes différences dans leurs présuppositions sur la nature humaine et sur les relations entre les individus ont façonné leur conception quant aux connaissances à acquérir et sur la manière dont les élèves apprennent. Cette étude qui s'appuie sur la méthodologie préconisée par de R. G. Collingwood expose ces différentes présuppositions et met en évidence, parmi les spécialistes en éducation, l'existence de trois systèmes d'idées prédominants et conflictuels. Sans être apparentes, les idéologies conservatrice, libérale ou collectiviste ont eu malgré tout un impact sur les réformes envisagées.

We thought much alike on many things.

... We were in disagreement on very, very, few points."1

Deep differences in ways of thinking about what students needed to know and how they learned contributed to the problems Alberta's educational leaders encountered in their efforts to promote and implement progressive reforms between c. 1920 and 1950. Although these leaders believed that they thought very much alike and undertook what appeared to be a collective and "systematic attempt to sell their revision,"2 
analysis demonstrates that these leaders had fundamental and conflicting differences in their world views. Borrowing from an intellectual history approach, which takes the position that human action is mediated by thought and that ideas are "a major force in shaping historical events," 3 and utilizing a method of inquiry advocated by R. G. Collingwood, I uncover in this study the particular views of the world, human nature, and the relationship among human beings held by educational leaders who worked in Alberta during the first half of the twentieth century. This study reveals that ways of thinking or ideas were an invisible but significant factor in shaping educational reform efforts.

Although the term "progressive education" has been disputed because a concise description of what this entails has not emerged, ${ }^{4}$ Canadian educational historians have used this label as a descriptor, providing insights into progressive reform efforts undertaken across Canada ${ }^{5}$ and offering a variety of explanations for the unsuccessful, partial, or patchwork implementation of progressive curricular and pedagogical approaches between 1920 and 1955. For example, Robert Patterson proposed that a lack of commitment by policy-makers ultimately led to lacklustre implementation efforts across Canada. ${ }^{6}$ Robert Stamp argued that the war effort, which reshaped socioeconomic circumstances in Ontario, led to a reconsideration of the need for new approaches to curriculum and instruction, and he asserted that political change - that is, the election of a Conservative provincial government that replaced the Liberals in 1943 - "marked the death-knell" of curricular reform. ${ }^{7}$ Amy von Heyking argues that progressive reform in Alberta was shaped by the professionalization of educationists seeking ways to enhance classroom practice to meet the needs of learners and society, ${ }^{8}$ and she points out that "many elements of the revision, such as the use of the 'enterprise' teaching approach and the replacement of history courses with Social Studies endured in Alberta while other provinces returned to more traditional instructional methods after 1945."

Most historical studies have illuminated socio-political and economic factors that influenced curricular and pedagogical revisions, but there is a growing number of studies that specifically examine the ideologies that underpinned progressive reform. For example, Paul Axelrod argues that while Toronto educators' "approach was pragmatic [and] not deeply philosophical," they employed an amalgam of progressive and traditional approaches "within the political culture and dominant values of the province and the times." ${ }^{10}$ David Tyack categorized progressive educators according to their philosophical/political ideologies, labelling four groups including: administrative progressives, who were interested in reforming the governance of schooling through the application of scientific principles; pedagogical progressives, who concentrated on changing the curriculum and instructional methodologies; libertarians, who advocated that schools focus primarily on meeting the individual needs of individual children; and social reconstructionists, who sought to reform society by "instilling left-leaning ideology in schoolchildren." ${ }^{11}$ Theodore Christou provides powerful insights into progressive thought in Ontario between 1919 and 1942 through his examination of how ideas related to child study and developmental psychology, social efficiency, and social meliorism informed educationists' ways of thinking about 
active learning, individualized instruction, and the design of curriculum relevant to contemporary society. ${ }^{12}$ Christou specifically refers to three philosophical positions taken by Ontario progressives: administrative, pedagogical, and meliorist. Through examination of the differences in presuppositions among Alberta's educational leaders who promoted progressive revisions, this study will add another layer of understanding about how ideology influenced educational reform. In order to differentiate my study of presuppositions held by Alberta progressives from studies that have gone before, I will refer to three groups revealed during analysis of their written statements, each characterized by a dominant way of thinking: conservative, liberal, and collectivist. These groupings, and the corresponding labels I have chosen to use, are not necessarily generalizable to all progressive educators. Rather, the groupings and the labels are particular to the ways of thinking of the specific group of Albertan educational leaders examined in this study and I selected the labels as a shorthand method for referring to each group.

My investigation is framed by understandings that come from the point of view of intellectual history, which aims "to promote understanding of the complexity, even the disorder, of our past development as thinking beings." ${ }^{13}$ R. G. Collingwood argued that "all history is the history of thought [and that] human actions can only be knowable as the outward expression of thoughts. ${ }^{14}$ Like Collingwood, I am not only interested in "knowing what people did, but understanding what they thought." 15

For this study, I examined the ways of thinking of the group of educational leaders who worked in Alberta between 1920 and 1955. The group includes school inspectors and other members of the provincial department of education, normal school instructors, members of the executive of the Alberta Teachers' Association (ATA), and members of the Edmonton and Calgary education societies. By focusing on educational leaders, I was able to examine the thought of a group consisting of a relatively small number of people, approximately forty to fifty individuals at any one time. These individuals had similar backgrounds in life experience, education, and work experience. The majority of group members were men, which should not be surprising considering the fact that during the time period being studied most women left the teaching profession before advancing to leadership roles, because only unmarried women were expected to continue to follow a career. While biographical information was not available for all group members, ${ }^{16}$ the information that was accessible indicates that most members were middle-class Anglo-Protestants who had been born and raised in eastern Canada - predominantly Ontario and the Maritimes. The majority held at least one degree granted by a Canadian university and had done graduate work at American universities, in particular Columbia, University of Chicago, and Stanford. Most group members began their careers in Alberta as teachers, but rapidly moved into higher positions in the educational hierarchy, becoming school inspectors and normal school instructors, for example. Group members generally had lengthy careers within the Alberta education system, remaining employed in various departmental or affiliated positions for many years.

These people held positions in the education system that allowed them to have a direct impact on educational policy-making, curriculum development, and the 
training and supervision of teachers, and they produced a relatively large body of written work, including Department of Education annual reports, textbooks, articles, lectures, speeches, and letters, explicitly expressing their opinions and positions regarding contemporary educational issues. This type of preserved material provided me with sources that allow insight into the thought of these historical agents at the time when they were doing their thinking.

The methodology I used to reconstruct the educational past is based on R. G. Collingwood's suggested approach, which includes re-enactment, interpolating, and interrogating. Robin George Collingwood, who worked as an archaeologist, historian, and philosopher in England, between c. 1912 and 1943, developed his conception of history and epistemological approach to counter the predominant influence of logical positivism apparent in the early twentieth century. Collingwood, among others, advanced an epistemology that supported the validity of historical knowledge. He contended that the natural world can be understood through that which is observable, while human affairs are "primarily concerned with the meaning of human action, and action is the unity of the outside [observable] and the inside [thought]."17 Hence, Collingwood maintained that historical investigations should aim to make the implicit explicit — or turn the inside out — and he developed a methodology for using primary source documents and relics as evidence to reconstruct both the outside and inside of past human actions. He argued that historical knowledge is constructed through a dynamic process involving the acts of questioning; rethinking the thoughts of others by reading, criticizing, and corroborating their written work; and reflection. He contended that knowledge and understanding are, and must be, constantly recreated by active processes of thought, three of which became the main features of his approach to "doing" history: (a) re-enactment ${ }^{18}$ — rethinking the thoughts of historical agents in the effort to understand what they meant; (b) interpolating ${ }^{19}$ — filling in the gaps; and (c) interrogating ${ }^{20}$ — asking questions of the sources, including, "What does this mean?"

Unique and fundamental to his approach, Collingwood explained that re-enactment is an active process that involves the effort to determine the internal sources from which the thinking derived. He argued that "you cannot find out what a man means by simply studying his spoken or written statement. ... In order to find out his meaning you must also know what the question was to which the thing he has said or written was meant as an answer." ${ }^{21}$ Re-enactment, therefore, requires that the historian determine the specific problems or questions that historical agents were addressing in order to gain insight into the internal sources from which their thinking derived. Collingwood claimed that we can know what the problem or question was "by arguing back from the solution." 22 In other words, because statements made by historical agents represent the solution to the problem they were addressing, historians can use these statements and interpolate back to the problem, even if the agents did not explicitly express the question they were asking. Determination of such questions assists the historian in uncovering the belief system, or cluster of presuppositions, held by the thinker. These presuppositions, or ideas that people took for granted, affected their inquiries into whatever specific aspect of the world they were 
particularly interested in. To understand the thought of historical agents, historians must not only uncover the questions that guided their inquiries but must also use this understanding to uncover the presuppositions which affected the formulation of the questions they asked. ${ }^{23}$

To highlight differences in thinking about progressive reforms, I utilized Collingwood's methodological approach to determine specific questions that were addressed by Alberta's educational leaders in their written statements, which in turn reveal the presuppositions held by these educators. For the purposes of this paper, I focus on three groups of questions to which their written statements were a response, including:

(a) What is the purpose of education? What should educating for responsible citizenship entail?

(b) What should be taught, including subjects, content, skills, attitudes, and/or behaviour?

(c) How should this be taught? Should approaches include "hands-on" and experiential learning and development of critical thinking?

While Alberta's educational leaders appeared to be acting in concert, making similarsounding statements regarding the need for a progressive program and approach, my analysis makes clear that what individuals and groups of individuals meant when they made statements about curriculum and pedagogical reform depended upon their way of thinking, which arose from their particular presuppositions about society and human nature. Although I did attend to incoherencies and inconsistencies in ways of thinking of individuals, and individuals within the groups, my analysis reveals three predominant ways of thinking circulating among Alberta's educational leaders that arose out of the ideas they took for granted. For ease of discussion, I use the following labels to identify three groups of leaders who I categorized based on their dominant ways of thinking: (a) conservatives, those who sought to preserve "institutions and practices that have withstood the test of time;" 24 (b) liberals, those who embraced the idea that individuals "are born with the capacity to reason, and with a corresponding responsibility to assess their society;" 25 and (c) collectivists, those who believed that "society is unhealthy - indeed, that its very survival is threatened - because the traditional mechanisms developed by society to contend with social problems are incapable of doing their job." ${ }^{26}$ I posit that coming to understand more about how implicit, hidden, or "inside" ways of thinking shape "outside" behaviours offers another layer of insight into the nature of progressivism and, while I recognize that there are other classification systems used for grouping varieties of progressive thought, I think the labels I have chosen to use are a good reflection of the particularities of each group's set of presuppositions - ways of thinking that will be clarified in the following discussion. Please note that quotations in the discussion are acknowledged both in the endnotes and by inclusion of the name of the individual who made the statement (in parentheses). This technique was employed so the reader can discern who made particular statements without having to refer to the endnotes. 


\section{What Is the Purpose of Education?}

The written statements of all Alberta progressives reveal a common thread regarding their beliefs about the general purpose of education - that is, all wrote about education as a means of developing responsible citizens. However, their statements also reveal some subtle and some stark differences in thinking about responsible citizenship and the role schooling should play in developing citizens.

\section{Conservatives: What Is the Purpose of Education?}

Alberta's conservative educational leaders presupposed that society was an organic hierarchy "where each one, leader or follower, plays his part, nor thinks for a moment that in the long run he can live unto himself" (Coffin). ${ }^{27}$ These leaders assumed that the purpose of education was to develop individuals as members of society who would be loyal to the nation, supporting the state emotionally and economically according to their capacities - capacities that were assigned to them according to the societal role or social class into which they were born. For example, G. Fred McNally stated:

If all were destined to become citizens, the State obviously had a right to expect that each youth would have his native abilities and aptitudes developed to the maximum of which they were capable. Not just the brilliant, the academic minded, the financially fortunate, those destined to be doctors and lawyers and the families of the "best" people, but everybody capable of mental achievement, let it be never so slight. ${ }^{28}$

Conservatives believed that the general purpose of schooling was to educate responsible citizens who developed "habits of self-discipline and the accompanying understanding of the reasons for regulations" (McNally). ${ }^{29}$ Good citizens should "have a knowledge of our institutional life" (Robertson) $)^{30}$ - that is, at least "an elementary understanding of society and government and [the wherewithal] required for an intelligent reading of a newspaper" (Wilson). ${ }^{31}$ Conservatives argued that schools should take a pro-active role in "the bringing about of this sense of national solidarity, this spirit of mutual confidence, this pride of national accomplishment and disposition to good neighbourliness so much to be desired" (McNally). ${ }^{32}$ As the primary vehicle through which children would receive "the benefit of an inspiration to become a loyal Canadian citizen" (Hill), the school should offer instruction that would teach students about their "privileges and responsibilities as a citizen of Canada" (Ross), improve "appearance, manners, ... and adoption of Canadian sentiments" (Russel), show "how to make the best use of this leisure time" (Coffin), and assist in the development of the capacities of students, let them be "never so slight," to allow them to fulfill their appropriate roles in the economy and society that had been established in the nation. ${ }^{33}$ "To do less than this meant that the State was being short-changed and potential sources of national strength left dormant" (McNally). ${ }^{34}$ For conservative educational leaders in Alberta, education should aim at the inculcation of particular 
ideas such as loyalty, duty, deference, and service along with the development of skills and capacities that assisted individuals in becoming useful, serving members of society, even if they were not from families of the "best" people.

\section{Collectivists: What Is the Purpose of Education?}

In statements that sound similar to those written by conservatives, Alberta's educational leaders that I have labelled as collectivists indicate that they also believed that the purpose of education was to develop the individual as a member of society. However, examination of their statements demonstrates that these Alberta educators had social change as their ultimate goal, rather than maintenance of the status quo. Collectivists presupposed that an organic, co-operative, egalitarian society would emerge when individuals developed social intelligence and learned to act together to bring about social change. These educators claimed that good citizens recognized that "social individualism is a primitive kind of behaviour ... [and that] civilized behaviour is cooperative" (Dickie). ${ }^{35} \mathrm{~A}$ responsible citizen developed "his capacities not only as an individual but as a member of society" (Newland), recognized "his collective responsibilities and the privileges which are his by virtue of that association" (McDougall), understood the "social purpose of democracy," and directed his or her "intelligence toward social welfare" (Newland). ${ }^{36}$

Collectivists argued that "the significant factor here is the restraint imposed upon the social group [was] by the social group itself in order that the social group may have the power to affect an adjustment which its separate units could not have achieved individually" (McDougall). ${ }^{37}$ They took for granted that individuals could be melded together as a co-operative organic unit, and when this occurred, a combined collective or social intelligence would emerge which could then be directed towards social change or social reform. For them, then, the purpose of education was to develop individuals as members of society who would, as members of a co-operative collective, "solve their social problems and ... make a useful contribution to the solution of the problems of the community" (Dickie). ${ }^{38}$

Collectivists argued that schools should take a pro-active role to "not only interpret the basic social purpose of democracy - the welfare of all the people — but also serve to polarize the will of our society to achieve that purpose" (Newland) ${ }^{39}$ While collectivists were not worried that development of critical thinking might lead individuals to question the traditional social order - after all, it was the old order they wished to reform - they were concerned that critical thinking might lead individuals to decide that they were not willing to relinquish personal interests in favour of the interests of the group. Collectivists were determined that schooling should be aimed at melding the potential human resources of the country into unified action without arousing questions about the sacrifice of personal interest. Hence, as the primary vehicle through which children would be "trained to function efficiently in a democracy" (McDougall) and receive "training in group living" (Dickie), they believed that the school should provide an environment that would encourage "the integration of the behaviour of the learner into socially desirable patterns ... [and develop] both attitudes and abilities conducive to the well-being of the social group" (McDougall)..$^{40}$ 
Because collectivists believed that socially intelligent activity, or "true" intelligence, could not be produced without a conformity of behaviour and attitudes that melded people together in an organic unity, they maintained that development of social behaviour and attitudes and social intelligence was the main purpose of education.

\section{Liberals: What Is the Purpose of Education?}

In contrast to the first two groups discussed, Alberta's liberal educational leaders presupposed that society was an amalgam of atomistic and fundamentally rational individuals rather than an organic collective. Examination of their written statements demonstrates that this group emphasized education as personal growth rather than the development of the individual as a group member.

Liberals took for granted that individuals were capable of understanding the cultural traditions from which the present society arose and were able to improve society by understanding great truths and principles and critically "evaluat[ing] both the old and the new" (Lazerte). ${ }^{41}$ They took for granted that individuals were rational and could develop the "power to think" (Doucette), and that "given the best laws, with the best governments and the best institutions that human intelligence can evolve the task of making something of himself remains with the individual" (Baker). ${ }^{42}$ Liberals believed that a responsible citizen had "an understanding of the great truths," "faith in his own judgement, ability to evaluate, and an unwillingness to accept uncritically what he is told and what he reads" (LaZerte). ${ }^{43}$ A good citizen was "a splendid individual, his powers of body and mind fully developed, his character sound and noble" (Baker) ${ }^{44}$ and, as individuals who were "self-reliant, critical and non-conforming," responsible citizens were "equipped with knowledge, with appreciation of our culture, and possessing disciplined intellectual powers" that allowed them "to read intelligently, write clearly, speak affectively, reason quantitatively, think logically, and exercise correct judgements" (Doucette). ${ }^{45}$

Liberals believed that schools had the obligation to assist "a child growing up in a culture [to] learn the essential elements of the culture." Andrew Doucette stated, "The function of school is threefold. (i) It must transmit the culture, (ii) it must maintain the culture, and (iii) it must improve the culture." ${ }^{46}$ However, liberal educators did not think that the school was responsible for determining the specific direction for improvement taken by society. They believed that this direction would be determined by individuals who understood the culture and who were able to think rationally about social reform. As the primary vehicle through which children would learn to think, the school should provide students with something to think about by offering instruction in a variety of subject matter. Based on these assumptions, this group of educational leaders believed that the primary purpose of education was to prepare "people to think for themselves" (Doucette). ${ }^{47}$

\section{Summary: What Is the Purpose of Education?}

In responding to the question about the purpose of education, the written statements of Alberta's progressives reveal a common belief that education should be aimed at developing responsible citizens. However, their statements also reveal that each group 
held particular beliefs about responsible citizenship and the role of schooling based on their differing presuppositions. Conservatives believed that education should aim to inculcate ideas such as loyalty, duty, deference, and service and to develop skills and capacities so individuals would become useful, serving members of society. Collectivists, with their supposition that socially intelligent activity could not be produced without a conformity of behaviour and attitudes, believed that schooling should aim at developing appropriate social behaviour and attitudes and social intelligence in students. Based on their assumptions, liberals believed that the primary aim of education was to help individuals learn to think for themselves.

\section{What Should Be Taught and How?}

While all Alberta's educational leaders made statements indicating a belief that what should be taught should include a balance of knowledge, thinking skills, social behaviour, morals, attitudes, and practical skills, their written statements also make clear their beliefs about which of these should be most strongly emphasized. The "what" learning that was emphasized by each group was related to their beliefs about the purpose of education and their beliefs about the capacities of learners. Each group's ways of thinking about how teaching should proceed was also shaped by their beliefs about these issues. In addition, ways of thinking about methodology were influenced by philosophies of knowledge, ideas about the mechanisms of learning, and beliefs about the ability to identify the capacities of learners that were held by each group.

\section{Conservatives: What Should Be Taught and How?}

Conservatives believed that practical, vocational, and manual training should be the major focus of schooling, and these educators emphasized the need for a practical orientation in the teaching of traditional subject matter. They argued that children should receive "adequate training in the things essential to a practical education; oral reading with proper expression, the spelling of words in common use, writing composition in its relation to letter writing, accuracy and rapidity in the use of the simple rules of arithmetic" (Aylesworth).$^{48}$ Arithmetic teaching should include problems that have "practical value to the child" (Smith) and "sufficient thought [must] be given the seat work to relate the problem to the experiences of everyday life" (McNally). ${ }^{49}$ Geography teaching should help "pupils realize that the earth and what is on it form a living, progressive, developing organism of which mankind is the centre of interest" (McNally). ${ }^{50}$ History teaching should focus on "civics in order that the Canadian boy and girl may grow up with a clearer idea of the nature of the government under which they live" (Nelson), or be "approached from the guidance side," emphasizing "the privileges and responsibilities for the individual citizen and his relation to the group, rather than on the machinery used" (McNally). ${ }^{51}$

Conservatives also stressed that new subjects should be introduced or strengthened in the school program even if "this probably may involve the sacrifice of some less important subject of the curriculum that is related to purely mental training" (Ross)..$^{52}$ They advocated subjects such as "music, drawing, manual training, 
domestic science and physical culture" (Smith), "Hand Work, School Gardening, and Elementary Agriculture" (Boyce), "physical education" (Ross), "Agriculture and real Nature Study" (Nelson), "sewing, household economy, printing, [and] woodworking" (McNally). ${ }^{53}$

Conservatives argued for a practical orientation in the teaching of traditional subjects and the inclusion of vocational and manual training subjects, based on the belief that this type of education was most useful for the majority of the students in their schools. They argued that because "responsibility to youth extends beyond the time they are in school ... we can profitably spend time and money and brains in seeking to prepare young people better for the work they are going to have to do anyway" (McNally). ${ }^{54}$ They believed that educators should realize "that it is at least one of their important duties to equip the boys and girls, under their charge, for doing the practical work of life" (Aylesworth), and asserted that educators should become "conscious of the limitation of the regular Academic Courses in satisfying the requirements of young people competing for employment," and develop programs that focused on "utilitarian subjects of study" (Carpenter). ${ }^{55}$ After all, they argued, "The training of the pupils in the correlate use of hand and eye in the manipulation of tools and materials gives them a remarkable readiness of adaptability in any field of activity where such skill is required" (Smith) ${ }^{56}$ Conservatives argued that vocational and manual training was a must for the majority of children in order that they develop "personality, selfcontrol, initiative and appreciation, and habits of industry and love for productive and constructive work" and "a degree of industrial intelligence and adaptability" (Smith). ${ }^{57}$

In their urgent support for vocational and manual training, conservatives reflected two of their fundamental beliefs: (1) that society required the contribution of the work of all people, no matter how humble their position; and (2) that the majority of people did not have the capacity to handle the academic curriculum. Conservative educational leaders in Alberta argued that a "saner view of relative values in life" would be developed by giving "a larger and more respectful consideration to the dignity of the man in overalls" (Carpenter) and to do this "some more effective means should be taken to stimulate greater interest in these subjects [school gardening, manual training, and household science] in all our public schools" (Smith). ${ }^{58}$ Although they believed that the "book-minded matriculant is better able to look after himself than are the larger numbers not so generously endowed, but none the less necessary, for all that, in the social order," they also professed that it was "high time the emphasis was shifted to at least give an equal opportunity to those who may not be so highly endowed with academic ability as with power to achieve" (Carpenter). ${ }^{59}$ They argued that if the aim of education was "to develop to capacity all pupils who came to us [it seemed] unfair that academically-minded students should receive all the attention of school authorities." G. Fred McNally stated,

In some way an elite standing must be established [for vocational education], comparable in prestige to that of matriculants. In so doing we shall not only promote the happiness of countless numbers of our citizens but shall be assisting in the development of our most important resource, people. ${ }^{60}$ 
Conservatives advocated an approach in which "merely learning no longer occupies so much of the attention of pupils ... The joy and power of doing useful work [should be] placed on the same level as the pleasure that comes from earnest study" (Scott) ${ }^{61}$

In formulating their approach, this group of educators took for granted that "some have inherited brains and nerves which possess greater impressibility, greater retentivity, greater educability in short, than those of others" (Sansom). ${ }^{62}$ They claimed that "a vast waste of energy and money is incurred through the attempt to carry along together, often in overcrowded rooms, work for pupils of the most varied qualifications, conditions of life and possibilities" (Coffin) and therefore advocated the development of non-academic programs to meet the needs of learners with lesser abilities. ${ }^{63}$

This group advocated an approach to be used in the teaching of "this ninety per cent" (McNally) of pupils with lesser ability that included: (1) the teaching of subjects "in a practical way," with the content "illustrated by more experiments and more closely related to life" (Schoffield); (2) the development of "the powers of observation" (Scott) combined with the "opportunity to apply learning to practical problems" (Tingley); (3) an emphasis on "doing combined with learning" where "the constructive abilities of boys and girls" are developed "by the handwork of all kinds" (Scott); (4) the opportunity for "much sense-experience and freedom for selfexpression in creative activities, such as drawing and constructions" (Frame); and most importantly, (5) the structuring of "courses that will offer experiences which are closely integrated with environment needs" (Tingley) and programs that "make provision for tool using experience on the part of boys and girls, [along with] consideration of and participation in the practical problems likely to arise in the course of their lives as men and women" (Carpenter). ${ }^{64}$

While conservatives made statements indicating their belief that appropriate teaching and learning procedures would take into consideration the developmental level and experiences of learners, their statements also indicate that they took for granted that the capacity of learners was fixed according to the level of society into which they were born. Believing in this "fixedness" of learner capacity, they advocated an activity-based, experiential, and practical course of study for most learners. While they argued that their approach was designed to meet the needs of the learner and was therefore "child-centred," their approach was actually similar to the traditional approach in that it involved teaching particular kinds of subject matter to particular kinds of learners. They did not advocate analysis of the interests, needs, and abilities of children or design curricula and methods to assist the development of such interests and abilities, but rather argued for the streaming of children and youth into courses of study that would "meet their needs." In other words, these educators focused on the type of subject matter - that is, practical and skill-oriented - and how it should be presented, rather than on developing programs and pedagogy responsive to the specific needs and interests of children and youth. Hence, while they could and did argue in favour of progressive reforms to curriculum and instruction, the underpinning suppositions that supported such arguments came from their conservative world view. 


\section{Collectivists: What Should Be Taught and How?}

With their beliefs regarding the purpose of education, collectivists argued that there should be a de-emphasizing of subject area content. While they accepted that skills and knowledge training were an important part of education, they maintained that "the learning involved is to be social and appreciational rather than informational" (Newland). ${ }^{65}$ In de-emphasizing subject matter, collectivists focused on meeting the needs of learners by assisting them "with their personal adjustment to group living" (Newland). ${ }^{66}$ They argued for an approach that centred on assisting in this adjustment, an approach where "the method is experience and the material is social situations" and where learners were not to be presented with "a list of facts to be learned but a series of social situations to be dealt with" (Dickie) ${ }^{67}$ In the context of these social situations, learners would not only acquire information that was useful in solving social problems, they would also develop the skills, habits, attitudes, and behaviours necessary "to become an accepted member of the social group" (Dickie). ${ }^{68}$ Traditional subjects would be replaced by enterprise and social studies, and these experiential or activity-based subjects would be taught in such a way as to "relate the instruction to the experience of the child through project and socialized work" (Gibault). ${ }^{69}$

Enterprise studies, which were to be implemented at the elementary school level, were "merely a unit of ordinary living carefully planned and carried out as an experience in intelligent living" (Dickie). ${ }^{70}$ The enterprise approach involved "socialization, and projects which would bring out greater activity on the part of the pupils" (Crispo), giving "the pupil's creative work a public and cooperative purpose" (Dickie) and engaging pupils by involving them "in problem-solving situations or enterprises, where the pupils know why they are doing what they are doing" (McDougall). ${ }^{71}$ Social studies, which was for intermediate and senior high students, would also involve solving community problems with a "flexible topical arrangement of the content" which makes possible "the study of politics, ... social development and current events, when and as they are alive and hot" (McDougall). "Social Studies represent, on the side of content, a fusion of Geography, History and Civics. On the activity side, however, they will include Music, Art, Dramatics, Literature, Health and Science" (Newland)..$^{73}$

In taking for granted that "knowledge has little to do with thought ... [that] knowledge is only that which results from sensory input" [for example that] "a person learns to blush, to stammer, to lose his temper, to be morbid about sex, to go into hysterics, yes, even to go insane, in the same way he learns to talk, or laugh, or read, or do arithmetic" (Newland), collectivists argued that "learning is psychologically a process of interaction between the individual and the social and physical environment for the purpose of solving a problem to meet a need" (Newland). ${ }^{74}$ They argued that the development of the whole child occurred when the children learned "to adjust themselves satisfactorily to any social situation in which they find themselves" (Dickie) ${ }^{75}$ and that social intelligence would only emerge in the context of social situations.

Hence, the specific methodology advocated by collectivists included: (1) "the preview period in which the teacher chooses or creates the situation and prepares a 
preview of the way in which he thinks it likely to develop"; (2) "the presentation of the situation to the pupils in such a way as to insure their discovery of it as one which affects them personally and about which it behooves them to take some action"; (3) "the planning period in which the pupils discuss their undertaking, first, to decide upon the goal that they wish to achieve, and secondly, to analyze the main problem to find out what sub-problems must be solved in order to attain the desired end" and "set down a statement of the main problem" (Dickie); (4) the working towards the solution of the problem "by means of group discussion [and] group search for information" (Newland) in "committees, each committee making a careful study of its own part of the problem, and acquiring only a general knowledge of what other committees are doing" (Dickie); and finally, (5) the development of a solution to the problem, where students learn "to loyally accept responsibility for a decision based on the considered opinion of the majority of the group" (McDougall). ${ }^{76}$

While collectivists did advocate for active learning in a child-centred program, this was based on their belief that education must ensure appropriate social behaviour, not autonomous critical thinking. The activity program was to be designed to teach students to "act intelligently." This included teaching students to "recognize a group purpose, to analyze it together, and by co-operative inquiry to seek the surest means of attaining it" (Dickie). Independent critical inquiry was not to be encouraged because the student's "experience is too narrow to enable him to form or to apply generalizations or principles for himself" and because "social individualism is a primitive kind of behaviour" (Dickie), one that undermined the social discipline required for the implementation of a "true" democracy. Although Alberta's collectivist educators made statements that indicated their concern with the development of the whole child, it is clear that their child-centred approach was focused more upon adjusting the individual to the social group than on analyzing the ways in which individuals thought about and reacted to experiences and activities.

Collectivist Albertan educators promoted a child-centred activity program because they also took for granted that the majority of people did not have the intellectual capacity to engage in the kind of critical thinking that would lead to an understanding of the need for personal sacrifice. They argued that "all pupils cannot do equally well academically, but all must be afforded the opportunity to make their maximum contribution," and therefore schooling must be "broadened to include the pupil as personality. When the personal adjustment of the individual to his environment is affected, the academic phase takes care of itself" (McDougall). ${ }^{77}$ They maintained that "all but a very few specially situated or specially talented children need training in social behaviour in order to enable them to adjust themselves satisfactorily to the complexities of modern life" (Dickie) and that if the schools could increase the level of understanding of social realities among the "two-thirds [who] are of average or near-average intelligence" and "imbue them with co-operative attitudes towards social welfare, the dilemma of democracy can be resolved" (Newland). ${ }^{78}$ In other words, collectivists did not believe that the majority of people were capable of appropriate critical thinking, and therefore socially intelligent activity or behaviour should be induced through training that occurred within social situations. 


\section{Liberals: What Should Be Taught and How?}

Liberal educational leaders in Alberta stressed the need for the maintenance of classical or traditional subjects, including for example, "English Literature, English Composition, Mathematics, Classical Languages, Physical Sciences, Geography, History, Political Science, in order to ensure that students were provided with a liberal education' [which gave] young people an appreciation of the spiritual and cultural heritage of mankind" (Doucette). While these educators did not completely oppose the introduction of new subjects in the course of study, they argued that "child learnings in Social Studies, enterprise, projects and unit studies must be put together. There is a danger that random units and projects leave too many gaps and children do not comprehend the whole of geography, of history, of the world" (Doucette). ${ }^{79}$ In addition, they warned, "Attitudes have no meaning unless rooted in information and knowledge." M. E. LaZerte stated,

I think we have to have a perfect balance and integration of skills, knowledge and attitudes. If inexperienced people are told that the emphasis is on attitudes, there could be a tendency to minimize the role of knowledge. ${ }^{80}$

Members of this group also recognized the demand for a practical education, that "the business world demands a showy facility in [arithmetical] computation," but argued that "the trained thinker ... could in a couple of months, acquire the necessary speed in mechanical work" (LaZerte) ${ }^{81}$ Liberals acknowledged that "there is a need for special trade training of carpenters and stenographers and for professional training of dentists and architects," but asserted that:

The person who has mastered mathematics or a foreign language, or correct written expression ... and knows the why of such learning has developed a pattern of clear thinking that carries over into life, and will be valuable in the maintenance of an orderly home, in decorating a store window, or in acting as a private secretary to a business executive (Doucette) ${ }^{82}$

While they argued for the maintenance of traditional subjects and an emphasis on content, or "knowledge" to give students something worthwhile to think about, liberals also advocated child-centred learning based on the belief that learner development involved "understanding each child's needs and teaching him $[s i c]$ in a way that will meet those needs. It is not knowing all the answers; but is opening doors so children will want to find answers for themselves" (Doucette). ${ }^{83}$ These educators emphasized the need to actively engage students in the processes of thinking and reflecting. They argued that "the teacher must expect less of himself and more of his pupils. He $[s i c]$ must concentrate upon the cultivation of habits of accuracy and order, the development of power to attack a task and right attitude of self-criticism of the task once completed" (Wilson). ${ }^{84}$ Arithmetic teaching should not "tell the child number facts and have him parrot them back to us" but rather should "create for him a natural number situation that to him would have meaning and through 
which he could think his way" (LaZerte). ${ }^{85}$ History, civics, and geography teaching should not be treated "simply as text-book subjects"; instead, teachers should focus on "directing and encouraging their pupils in habits of independent thought and discussion" (Russel), and other traditional subjects including literature, philosophy, art, and music should "train in critical and constructive thinking, give insight into moral, aesthetic and spiritual values, [and] train in citizenship in a free and changing society" (Doucette). ${ }^{86}$

Liberals argued that methodology should develop out of an understanding of the needs and ways of thinking of individual learners. Liberals reasoned that "if the student is having difficulty ... it was rooted in certain specific causes" and argued that teachers must understand the subject matter and each child and develop procedures that were "particularized enough to a child's particular type of thinking and his particular errors" (LaZerte). ${ }^{87}$ These educators counselled teachers to "observe children carefully. Note the traits and interests of each. Watch the physical and mental changes from week to week. Force yourself to attend to your pupils more than to your books" (LaZerte), in order to "learn how to live happily with youngsters and to teach them with understanding" (Doucette). By engaging in the analysis of the needs of individual learners, and using "the classroom as an educational laboratory" (LaZerte) by "testing, trying new methods, and re-testing" (Doucette), teachers could organize ideas, concepts, and generalizations "in terms of their inherent difficulty, the past experience and the present capacity of students," and develop procedures with "room for adaptation to individual differences" (LaZerte).$^{88}$

Based on these beliefs, liberals advocated for a methodology that was "dynamic and ever changing." Because they believed that methods "are discovered not imitated," these educators claimed that teaching and learning procedures should be developed by classroom teachers who engaged in "study, investigation and experimentation" (LaZerte). ${ }^{89}$ While liberals did think that the activity and experience involved in enterprise procedures assisted in learner development, they stressed that these "have no magical value" and that "the co-operative group activity of the enterprise often leaves too little room for adaptation to individual differences" (LaZerte). ${ }^{90}$ Liberal educators did not believe that a single or uniform methodology was adequate to meet the needs of individual learners. They claimed that all types of teaching and learning procedures had merit — including "good old fashioned drill" (Doucette), ${ }^{91}$ the use of textbooks, and enterprise procedures — and they cautioned against "having a highly specialized technique imposed upon" teachers (LaZerte). ${ }^{92}$

While liberal Albertan educators acknowledged that individual learners possessed differing capacities, they argued that the development of thinking skills was possible for all learners if teachers took into account "what research has discovered about individual differences, individual needs, and individual interests or aptitudes" (Doucette) and understood that "the type of remedial work we do is too theoretical and too overhead and not particularized enough to a child's particular type of thinking and his particular errors" (LaZerte). ${ }^{93}$ Although liberals accepted the notion that the ability of individuals might be related to their level of intelligence, these educators believed that if teachers mastered the basic concepts of the subjects they taught, they could 
organize "different sequences of experience for gifted children, for those of average intelligence, and for those of less ability." M. E. LaZerte stated,

... this can be done only by teachers who, day after day and year after year, experiment with different methods, try different organization of subject matter, and determine the relative difficulty that the mastery of given ideas and concepts presents for different levels of ability. ${ }^{94}$

Liberals insisted that "it is the function of the school to train the intelligences of all" (Doucette) and argued that if instruction was individualized and if students were required to exercise their thinking skills through the use of challenging questions "and quizzing everything they ever did or said," all students would develop "their own capacity to do some thinking" (LaZerte). ${ }^{95}$ They took for granted that learning involved connecting experiences and activities with concepts and ideas through the medium of thought. They argued that "ideas must always precede symbols; in fact, without the idea, a symbol is useless and empty of meaning" (MacGregor) and that "the role of activity is to give that background of experience in language, or science, or social studies or mathematics that will make the symbol carry a wealth of meaning" (LaZerte). ${ }^{96}$ They also presumed that "knowing is a process," that "in order to think, one must have something about which to think," and therefore held that "the manner and method of teaching and learning cannot be separated from the subject matter involved during the process" (Doucette). ${ }^{97}$

\section{Summary: What Should Be Taught and How?}

The examination of the written statements of educational leaders in Alberta reveals the particular dominant view of society and human nature held by each of the three groups and analysis demonstrates how these presuppositions shaped each group's thinking about what should be taught and how.

Conservatives took for granted that society was an organic hierarchy that functioned properly when individuals performed their duties within the roles assigned to them at birth. Related to this view, conservatives took for granted that some human beings were capable of rational thought while the majority were not, and that such capacities were predetermined according to the class into which individuals were born. Based on these presuppositions, conservatives concentrated on developing and implementing a program that focused on teaching practical or vocational subjects using experiential, hands-on methodology to ensure that all members of society developed their capacities to fulfill their inherited social roles and remain loyal to the hierarchical social order.

In comparison, the analysis established that collectivists took for granted that individuals could be melded together in a co-operative, organic, egalitarian society. Like conservatives, collectivists presupposed that some human beings were capable of rational thought while the majority were not, but in contrast these educational leaders assumed that when individuals learned appropriate attitudes and behaviours - that is, learned to adjust themselves satisfactorily - a collective social intelligence would 
emerge which could then be directed towards social reform. With these presuppositions, Alberta's collectivist educators concentrated on developing and implementing a program that focused on training in appropriate social behaviours and attitudes by using activity methods in social situations to ensure that individuals would sacrifice personal interest and work collectively towards social change.

Diverging from the other two groups, Alberta's liberal educational leaders took for granted that society was an amalgam of atomistic, rational individuals who shared in a similar culture and heritage and had an interest in the advancement of society. Liberals took for granted that all human beings were capable of rational thought, and that when educators took into account the particular needs, interests, and types of thinking of particular learners, this capacity for rational thought could be enhanced. In taking these notions for granted, liberal educators concentrated on developing and implementing a program that focused on helping students learn to think by offering them something worthwhile to think about and by utilizing a variety of particularized approaches that met the individual needs of learners and challenged them to think critically about the positive and negative aspects of the social system.

\section{Conclusion}

Although all Alberta's educational leaders took up the rhetoric of progressive education, working to sell the revision to teachers, parents, trustees, and the public at large, a deep analysis of their statements reveals that there were significant differences in how they defined progressivism and, consequently, differences in the degree to which they were committed to the new program and approach.

Collectivist leaders like Newland, Dickie, and Crawford defined progressive education as a method for transforming society, that is, for the creation of a new organic unity based on co-operation and equality. To bring about such a transformation, they believed that a progressive program must incorporate a complete change of attitude towards the content, methodology, and goals of schooling. These leaders believed that a progressive program should de-emphasize traditional subject matter, utilize the "learning by doing through group activity" approach, and focus on the development of co-operative, democratic behaviours and attitudes "to help people to learn how to live happily together in the world." With this definition and set of beliefs, this group of Alberta's educational leaders were completely committed to the progressive program first introduced in 1936 and worked towards a more extensive integration of subject matter, the implementation of activity-based group learning at all grade levels, and a reconstruction of the secondary program to "give adequate training for democracy" by offering more time "for 'social living,' more physical and social activities, and more opportunities for experience rather than mere knowledge." 98

Conservative leaders like McNally and Fuller defined progressive education as practical education. These leaders did not believe that the progressive program should aim at the transformation of society, but rather at meeting the needs of students by introducing practical or vocational training. Although conservatives adopted rhetoric similar to collectivists, their statements clearly reveal that they focused on those 
aspects of the new program that supported their beliefs about the need for "real life" experience, hands-on training, and a de-emphasis of academic subject matter for the majority of students, who conservatives believed to be incapable of handling academic work. While conservatives did not perceive the need for a complete change of attitude towards content, methodology, or goals, they did believe that there should be a change of attitude towards "matriculation subjects" and the "large numbers of students who have not the remotest chance of ever doing satisfactory work at the university level." 99 They believed that a progressive program could ensure efficient use of educational resources by utilizing new intelligence testing tools to stream students into courses that incorporated content and methods appropriate to their abilities and aptitudes. With these suppositions, conservatives were committed to those aspects of the new program that addressed the need for a practical education. While they were not particularly interested in a more extensive integration of subject matter or the implementation of activity-based group learning for all students, conservative leaders did work towards the implementation of an activity-based or hands-on methodology for those who would not benefit from "earnest study." These leaders promoted development and improvement of diagnostic tools and examinations for use in classifying students and endeavoured to enhance perceptions of practical and vocational courses in an effort to encourage students to take advantage of programs that would prepare them to become contributing members of society.

Alberta's liberal educational leaders, including LaZerte and Doucette, defined progressive education as "a means of implementing experimentalism." In other words, these leaders did not believe that progressive education represented a particular type of program or approach, but rather represented the ongoing search for better ways to help students learn to think by "testing, trying new methods, and re-testing." Because liberal leaders supposed that the transformation of society lay in the hands of individuals who were capable of rationally analyzing the system, they believed that progressive educators should aim at "understanding each child's needs" and at evolving methods to assist in the development of the intellectual power of individuals, rather than at supporting or tearing down the present social order. These leaders believed there should be a reorientation in attitudes towards content and methodology - a change in attitude that would encourage teachers to develop methodology by attending to how learners processed particular subject matter. In opposition to the collectivists, though, these leaders did not believe in de-emphasizing content, in the implementation of a particular pedagogical approach, or in focusing on the development of attitudes and behaviours. With their definition and set of beliefs, liberals gave conditional support to the progressive program because they believed that integration assisted in correlating "subject matter into a meaningful whole" and that learners could develop thinking skills and construct knowledge by engaging in concrete experiential learning activities. However, these leaders were not completely committed to the new program, because they did not believe that it represented "the 'last word' in educational method" or the perfect course of studies. They critically analyzed both the content and approach of the new program and worked towards encouraging teachers to develop and implement curriculum and methods based on 
an understanding of subject content and the processes by which all students could learn to think. ${ }^{100}$

These differences in ways of thinking, and consequent differences in the definition of progressive education, translated into difficulties in promoting and taking collective action towards the implementation of progressive programs in Alberta between c. 1920 and 1950. For example, although normal school instructors "all acted as public spokesmen for the program and familiarized their students with the methods," differences in ways of thinking resulted in presentations that indicated "varying degrees of support for the innovations." ${ }^{101}$

Under the guidance of Andrew Doucette, students of the Edmonton Normal School gathered evidence of these differences when they conducted a survey of staff members regarding their opinions about the new program. Although Doucette claimed there was "remarkably little difference of opinion to be noticed," the students detected three distinct shades of opinion and classified staff members into the following categories: (a) the "child-freedom group," who were completely committed to the new program, advocating "a large measure of freedom and autonomy for teachers and pupils," an emphasis on social attitudes, and the de-emphasizing of subject-matter; (b) the "enterprise-conscious group," representing "the moderate and popular point of view," committed to the use of the activity or enterprise approach and believing that "all other methods are secondary"; and (c) the "progressive education group," who were "subjectminded" and regarded "the enterprise as merely another, though important, addition to the battery of methods and techniques employed by the progressive teacher."102

It is not an enormous interpretive leap to presume that these differences in opinion affected the way normal school instructors presented ideas about the new program and approach to pre-service teachers. And it is not an absurd exercise of the historical imagination to argue that differences in presentation influenced the thinking of student teachers about the new program. Hence, it can be claimed that problems in the implementation of the progressive program and approach arose, at least in part, from differences in ways of thinking among educational leaders because even newly graduated teachers were affected by the variety of opinions about the benefits of such curriculum and pedagogy.

Although it has been argued that the implementation of a socially transforming progressive program and approach was stymied in Alberta by the fact that "a large section of the public did not support [educationists'] vision," 103 differences in ways of thinking among educational leaders themselves certainly contributed to the problems encountered in program implementation. While all leaders adopted the rhetoric of the progressive movement and presented similar ideas in speeches, lectures, and articles, they were in fact advocating the particular aspect of progressive education that matched their presuppositions about what and how students needed to learn. Thus, although there was the appearance that Alberta's educational leaders were taking collective action towards curriculum and pedagogical reform between c. 1920 and 1950, they were actually as divided in their opinions about the focus and methods of education as were other stakeholders. Ideas may be ethereal or invisible, but ways of thinking are significant factors in shaping educational reform efforts. 


\section{Notes}

1 LaZerte commenting on his relationship with Newland in B. T. Keeler and Marian R. Allison, interviewers, "A Conversation with M. E. LaZerte," ATA Magazine (November-December 1974): 33.

2 Amy von Heyking, "Selling Progressive Education to Albertans, 1935-1953," Historical Studies in Education 10 (1998): 69.

3 Doug Owram, "Writing about Ideas," in Writing About Canada, ed. John Schultz (Scarborough: Prentice-Hall Canada, 1990), 48.

4 Sol Cohen, Progressives and Urban School Reform: The Public Education Association of New York City, 1895-1954 (New York: Bureau of Publications, Teachers College, Columbia University, 1964); Herbert Kliebard, The Struggle for the American Curriculum, 1893-1958. (Boston: Routledge and Kegan Paul, 1986); Diane Ravitch, Left Back: A Century of School Reforms (New York: Simon \& Schuster, 2000); David Tyack and Larry Cuban, Tinkering Toward Utopia: A Century of Public School Reform (Cambridge: Harvard University Press, 1995); Arthur Zilversmit, Changing Schools: Progressive Education Theory and Practice, 1930-1960 (Chicago: University of Chicago Press, 1993).

5 Robert S. Patterson, "The Implementation of Progressive Education in Canada," in Essays on Canadian Education, ed. Nick Kach, Kas Mazurek, Robert S. Patterson, and Ivan DeFaveri (Calgary: Detselig Enterprises, 1986), 79-93; Jean Mann, "G. M. Weir and H. B. King: Progressive Education or Education for the Progressive State?" in Schooling and Society in Twentieth Century British Columbia, ed. J. Donald Wilson and David C. Jones (Calgary: Detselig Enterprises, 1980); von Heyking, "Selling Progressive Education," 67-84; Amy von Heyking, "Implementing Progressive Education in Alberta's Rural Schools," Historical Studies in Education 24, no. 1 (2012): 93-110; Robert Stamp, The Schools of Ontario, 1876-1976 (Toronto: University of Toronto Press, 1982); Patrice Milewski, “'The Little Grey Book': Pedagogy, Discourse and Rupture in Ontario in 1937," History of Education 37 (2008): 91-111; Paul Axelrod, "Beyond the Progressive Education Debate: A Profile of Toronto Schooling in the 1950s," Historical Studies in Education 17, no. 2 (2005): 227-241; Theodore Michael Christou, Progressive Education: Revisioning and Reframing Ontario's Public Schools, 1919-1942 (Toronto: University of Toronto Press, 2012).

6 Patterson, "The Implementation of Progressive Education," 79-93.

7 Stamp, The Schools of Ontario, 179, 182.

8 von Heyking, "Selling Progressive Education," 67-84.

9 von Heyking, "Implementing Progressive Education," 94.

10 Axelrod, "Beyond the Progressive Education Debate," 240-241.

11 David Tyack, The One Best System: A History of American Urban Education (Cambridge: Harvard University Press, 1974), 196.

12 Christou, Progressive Education.

13 Michael Biddiss in "What Is Intellectual History?" by Stefan Collini, History Today 35, no. 10 (October 1985), http://www.historytoday.com/print/7390\#sthash.tPJp0LQF. dpuf.

14 R. G. Collingwood, The Idea of History, revised edition with lectures, 1926-1928, ed. with introduction by Jan Van Der Dussen (Oxford: Clarendon Press, 1993), 115.

15 Ibid.

16 See Appendix A in Lynn Lemisko, “'Ideas' and Educational Change: The Thought and Action of Alberta Educational Leaders, 1905-1955” (Ph.D. dissertation, University of Calgary, 1998).

17 Collingwood, Idea of History, 213.

18 Ibid, Idea of History, 213, 215, 296, 328-329; R. G. Collingwood, An Autobiography (London: Oxford University Press, 1939), 31, 58. 66, 70; and R. G. Collingwood, An 
Essay on Metaphysics (Oxford: The Clarendon Press, 1940), 21-47, 59-60, 73-74, 76, 77.

19 Collingwood, Idea of History, 240-241.

20 Ibid., 242, and Collingwood, "Lectures on the Philosophy of History," in The Idea of History, 378.

21 Collingwood, Autobiography, 31.

22 Ibid., 70.

23 Ibid., 66, and Collingwood, An Essay on Metaphysics, 21-47.

24 Jerry Z. Muller, Conservatism: An Anthology of Social and Political Thought from David Hume to the Present (Princeton: Princeton University Press, 1997), 12.

25 Uday Singh Mehta, Liberalism and Empire: A Study in Nineteenth-Century British Liberal Thought (Chicago and London: University of Chicago Press, 1999), 52-53.

26 Michael Stephen Schiro, Curriculum Theory: Conflicting Visions and Enduring Concerns (Thousand Oaks, California: Sage Publications, 2008), 133.

27 University of Calgary Archives (hereafter UCA), Calgary Normal School Papers, UARC 0.002, E. W. Coffin, "Message from the Principal," The Comet, yearbook (1924-25), 7.

28 G. Fred McNally, "The Place of the School in Community Life," The School 32 (April 1944): 655 .

29 Ibid., 657.

30 Alberta Department of Education, Annual Report of the Alberta Department of Education (hereafter $A R$ ), 1922, 67.

$31 \quad A R, 1933,40$.

32 McNally, "Place of the School," 656.

$33 A R, 1910,48 ; A R, 1915,25 ; A R, 1927,35$; Coffin, "Message from the Principal," 7.

34 McNally, "Place of the School," 655.

35 Donalda Dickie, The Enterprise in Theory and Practice (Toronto: W. J. Gage \& Company, 1940), 70-71.

36 H. C. Newland, "A Sketch of Present-Day Education," Collected Papers, compiled by B. E. Walker (1968), 1; Newland, "What Have Educationists Learned from the War?" The School 32 (May 1944): 749; Newland, "Education Grows Up," Collected Papers, 6; University of Alberta Archive (hereafter UAA), W. D. McDougall Papers, 69-29, William D. McDougall, "Can Democracy Provide For Youth?” (c. 1941), 2.

37 McDougall, "Can Democracy Provide for Youth?”, 1.

38 Donalda Dickie, "Improving Techniques in Social Studies," The School 33 (April 1945): 673.

39 Newland, "What Have Educationists Learned from the War?," 749.

40 UAA, 69-29, McDougall, "Our Educational Point of View," nd, 2; McDougall, "Can Democracy Provide for Youth?", 3; Donalda Dickie, "Enterprise Education in Alberta," Education Digest 6 (September 1940): 43.

41 UAA, M. E. LaZerte Papers, 75-20, LaZerte, "Our Professional Responsibilities," (1953), 3

42 UCA, A. L. Doucette Papers, file 1.7, Doucette, untitled speech, nd, 12; Perren Baker, "The Place of Education in the Life of the Community," The UFA (September 1, 1922): 4.

43 LaZerte, "Our Professional Responsibilities," 3.

44 Baker, "The Place of Education," 4.

45 Doucette, untitled speech, 3 and 12.

46 UCA, file 5, Doucette, "Progressive Education Is an Interpretation of the Philosophy of Education known as Experimentalism," 2-3, nd.

47 Doucette, untitled speech, 3.

$48 A R, 1911,62$.

$49 A R, 1941,79 ; A R, 1911,54$. 
$50 A R, 1928,28$.

51 Ibid.; $A R, 1914,81$.

$52 A R, 1914,24$.

$53 A R, 1910,46 ; A R, 1910,49-50 ; A R, 1914,24 ; A R, 1915,127 ; A R, 1913,59$.

$54 A R, 1938,11$.

$55 A R, 1911,62 ; A R, 1935,83-84$.

$56 A R, 1910,46$.

$57 A R, 1915,95 ; A R, 1914,79$.

$58 \quad A R, 1931,93 ; A R, 1915,94$.

$59 A R, 1941,81$.

60 G. Fred McNally, G. Fred: The Story of G. Fred McNally, recorded by H. T. Coutts and B. E. Walker (Don Mills, Ontario: J. M. Dent and Sons [Canada], 1964), 109-110 and 114.

61 UCA, Calgary Normal School Papers, UARC 0.00, A. M. Scott, speech recorded in Alberta Normal School Souvenir (Spring 1911).

62 Clarence Sansom, "Intelligence and its Measurement," ATA Magazine 1, no. 9 (1920): 20.

$63 A R, 1916,28$.

64 McNally, "Place of the School," 655; $A R, 1929$, 43; Scott, speech; $A R, 1944,59 ; A R$, 1934, 58; $A R, 1941,81$.

$65 A R, 1936,16$.

$66 A R, 1943,26$.

67 Donalda Dickie, "Enterprise Education — Part I," B.C. Teacher (September 1940): 19;

Dickie, "Improving Techniques," 674.

68 Dickie, "Improving Techniques," 674.

$69 A R, 1934,57$.

70 Dickie, The Enterprise, 125.

$71 A R, 1934,51$; Dickie, "Enterprise Education in Alberta," 43; UAA, 69-29, McDougall, "Education for Modern Living," nd, 14.

72 UAA, 69-29, McDougall, lecture notes, nd, 3.

$73 A R, 1936,16$.

74 Newland, "The Functions of the University," nd, np, and "A Complete Change in School Subject Suggested," Calgary Albertan (February 9, 1934), np, in Collected Papers.

75 Dickie, "Enterprise Education - Part I," 19.

76 Ibid., 20; Donalda Dickie, "A Comment on the New Course of Study for Elementary Schools," ATA Magazine 17 (November 1936): 35; Newland, "The Enterprise Programme in Alberta Elementary Schools," address at General Session, Elementary Division, nd, np, Collected Papers; McDougall, "Our Educational Point of View," 3.

77 UAA, 69-29; McDougall, "The Administration of an Intermediate School," (1939), 14.

78 Dickie, The Enterprise, 80; Newland, "Education and Social Reconstruction," B.C. Teacher 23 (September-October 1943): 61.

79 Doucette, untitled speech; UCA, file 5.9, Doucette, "Liberal Education at the Secondary Level," (c. 1952), 2; UCA, file 6.19, Doucette, "The Road Ahead," nd.

80 M. E. LaZerte, "ASTA Interviews Dr. M. E. LaZerte," Alberta School Trustee 40 (August 1970): 27.

81 M. E. LaZerte, "Elementary Mathematics," ATA Magazine (Easter 1922): 30.

82 Doucette, "Liberal Education," 4, and untitled speech, 5.

83 UCA, file 5.11, Doucette, "Let Teachers Look at Themselves," nd, 2.

$84 \quad A R, 1932,37$.

85 LaZerte, "Elementary Mathematics," 30.

86 AR, 1916, 84; Doucette, "Liberal Education," 4.

87 LaZerte, "ASTA Interviews," 26. 
88 Ibid.; and LaZerte, "The Road Ahead," ATA Magazine (May 1959): 8; UAA, 75-20-3, LaZerte, "I Love Freedom,” nd., 11; “A Conversation with M. E. LaZerte," 32;

LaZerte, "President to Members," ATA Magazine 18 (October 1937): 5; UCA, file 2.6, Doucette, "Address to the Educational Progress Club," February 1, 1950, 3; UCA, file 5.9, Doucette, "Is Progressive Education Mediocre? A Defense," nd, 6.

89 LaZerte, "The Road Ahead," 8.

90 M. E. LaZerte, “The Enterprise Program — Its Validity," ATA Magazine (May 1936): 29.

91 UCA, file 1, letter, Doucette to Joel Rochon, January 18, 1954.

92 LaZerte, "I Love Freedom," 11-12.

93 UCA, file 6.9, Doucette, draft of "Modern Education in Alberta," for Trustee’s Magazine (October 1958); LaZerte, "ASTA Interviews," 26.

94 LaZerte, "The Road Ahead," 7.

95 Doucette, "Address to the Educational Progress Club"; LaZerte, "ASTA Interviews," 29.

$96 A R, 1934,61$; LaZerte, "I Love Freedom," 11.

97 UCA, file 5.10, Doucette, lecture (c. 1958), np; Doucette, "Address to the Educational Progress Club," 2.

98 Patterson, "The Establishment of Progressive Education," 164; Dickie, The Enterprise, 43; Newland, "Education and Social Reconstruction - Part II," B.C. Teacher 23 (November 1943): 61; AR, 1943, 16.

99 UAA, Education Society of Edmonton Papers, 73-18; Clarence Sansom, "A Proposal for the Reorganization of Secondary Schools," address to the society, nd, 5.

100 Doucette, "Liberal Education," 3; Doucette, "Let Teachers Look at Themselves"; LaZerte, "The Enterprise Program - Its Validity," 2; LaZerte, "The Road Ahead," 6-7. 101 von Heyking, "Shaping an Education," 192.

102 UCA, file 17.11, Doucette, "Attitude Toward the Enterprise Curriculum," nd, np. 103 von Heyking, "Shaping an Education," 220. 